УДК 159.9.072.43

DOI https://doi.org/10.23947/2658-7165-2021-4-1-51-61

\title{
Адаптация как фактор повышения успешности студентов в условиях социокультурных и образовательных рисков
}

\author{
Татьяна Н. Щербакова ${ }^{1^{*}}$, Хава Х. Тамасханова ${ }^{2}$ \\ ${ }^{1}$ Донской государственный технический университет, г. Ростов-на-Дону, \\ Российская Федерация \\ ${ }^{2}$ Ингушский государственный университет, г. Назрань, Российская Федерация \\ *E-mail: tatiananik@list.ru \\ *ORCID ID: https://orcid.org/0000-0002-4114-185X
}

\begin{abstract}
Аннотация
Во ввелении преАставлено обоснование актуальности исслеАования взаимосвязи алаптивности и Аетерминации успешности студентов в контексте современных рисков. Показаны результаты теоретического анализа субъективных факторов Аетерминант Аостижения успеха в стуленческом возрасте. Описаны основные направления проявления активности стулента, направленной на позитивные трансформации и саморазвитие. Аана солержательная характеристика роли преАставлений о способах развития аАаптивности мичности как фактора повышения успешности в условиях неопределённости. Новизна исслеАования заключается в выявлении и описании субъективных факторов успеха стулентов в условиях современных рисков. В солержание статьи включён сопоставительный анализ различных типов аАаптации и их эфффектов в практической активности развивающегося субъекта. РазАел Методы описывает методики и анкеты, используемые в исследовании. Описана выборка - студенты факультета психологии Аонского Государственного Технического Университета (АГТУ). В разделе Результаты показана роль рефлексии опыта аАаптации и Аостижения успеха в проектировании конструктивной инАивиАуальной траектории продвижения в учебно-профессиональной Аеятельности. В Аанном модуле содержится анализ критериев высокого уровня развития алаптИвности СтуАентов в Условиях современных рисков. В ОбсужАении результатов преАставлено описание и интерпретация результатов эмпирического исслеАования преАставлений студентов об аАаптивности и Аетерминантах Аостижения успеха в современных условиях. Аанные эмпирического исслеАования показывают значение представлений стулентов о факторах успеха в регуляции поведения и Аеятельности. Впервые показана роль развития инАивиАуальной мотивации роста и устойчивости Аичности в опреАелении проАуктивности повеАения стуАентов в Условиях современных образовательных и социальных рисков. В Заключении полчеркивается
\end{abstract}


наличие связи степени аАаптивности и успешности ^ичности студентов. Аелается выво А ТОМ, что уровень осмысления специфики проявлений неопределенности в современной ситуации способствует фрормированию устойчивости Аичности, ее продуктивности, жизнестойкости и конструктивности. ПривеАена модель программы повышения уровня алаптивности студентов как фрактора Аетерминации успешности студентов в современных условиях.

\title{
КАючевые слова
}

алаптация, студент, успешность, субъект, представления, субъективные Аетерминанты, аутопсихологическая компетентность, конструктивность

\section{Для цитирования}

Щербакова Т. Н.. Тамасханова Х. Х. Адаптация как фактор повышения успешности студентов в условиях социокультурных и образовательных рисков // Инновационная наука: психология, педагогика, дефектология. 2021. Т. 4, № 1. C. 51-61. doi: https://doi.org/10.23947/2658-7165-2021-4-1-51-61

\section{Adaptation as a factor of increasing the success of students in the context of socio-cultural and educational risks}

\author{
Tatyana N. Shcherbakova ${ }^{1}$, Hava H. Tamaskhanova ${ }^{2}$ \\ ${ }^{1}$ Don State Technical University, Rostov-on-Don, Russian Federation \\ ${ }^{2}$ Ingush State University, Nazran, Russian Federation \\ *E-mail: tatiananik@list.ru
}

*ORCID ID: https://orcid.org/0000-0002-4114-185X

\section{Annotation}

The Introduction provides a rationale for the relevance of the study of the relationship between adaptability and the determination of student success in the context of modern risks. The results of the theoretical analysis of subjective factors - determinants of success in student age are shown. The main directions of student activity aimed at positive transformation and self-development are described. The author gives a meaningful description of the role of ideas about the ways of developing the adaptability of the individual as a factor of hanging success in conditions of uncertainty. The novelty of the research is to identify and describe the subjective factors of students' success in the conditions of modern risks. The content of the article includes a comparative analysis of various types of adaptations and their effects on the practical activity of a developing subject. The Methods section describes the methods and questionnaires used in the study. 
The sample is described - students of the Faculty of Psychology of the Don State Technical University (DSTU). The Results section shows the role of reflection on the experience of adaptation and success in designing a constructive individual trajectory of advancement in educational and professional activities. This module contains an analysis of the criteria for a high level of development of students' adaptability in the conditions of modern risks. The Discussion of the results presents a description and interpretation of the results of an empirical study of students' ideas about adaptability and the determinants of success in modern conditions. The data of the empirical study show the importance of students' ideas about success factors in the regulation of behavior and activity. For the first time, the role of the development of individual motivation for personal growth and stability in determining the productivity of students' behavior in the conditions of modern educational and social risks is shown. In Conclusion, the author emphasizes the relationship between the degree of adaptability and the success of the students' personalities. The conclusion is made that the level of understanding of the specifics of the manifestations of uncertainty in the current situation contributes to the formation of the stability of the individual, its productivity, resilience, and constructiveness. The model of the program for increasing the level of adaptability of students as a factor determining the success of students in modern conditions is presented.

\section{Keywords}

Adaptation, student, success, subject, representations, subjective determinants, autopsychological competence, constructiveness

\section{For citation}

Shcherbakova, T. N., Tamaskhanova, H. H. (2021). Adaptation as a factor of increasing the success of students in the context of socio-cultural and educational risks. Innovative Science: psychology, pedagogy, defectology, 4(1), 51-61. doi: https:// doi.org/10.23947/2658-7165-2021-4-1-51-61

\section{Введение}

В контексте стратегических и операциональных трансформаций современной общественной жизни актуализируется интерес к выявлению социальнопсихологических и субъективных предикторов развития преадаптации личности студента как фактора обеспечения конкурентоспособности в условиях повышенной энтропии социальной и профессиональной жизни. Проблема психологических детерминант успешной преадаптации будущих специалистов приобретает сегодня особый смысл и актуальность. Это обусловлено рядом обстоятельств: повышенной динамичностью условий профессионального самоопределения, новыми тенденциями стандартизации и требованиями к компетентности субъекта, к уровню его психологической готовности 
к инновационным способам решения проблем, освоению новых технологий; изменением уровня притязаний современного молодого человека, ориентацией на расширение яичностных границ и повышения уровня жизни. С точки зрения современных психологов, сегодня востребована дичность, способная к самоинициации, надситуативной активности, нацеленной на достижение успеха, способная продуктивно решать «задачи на смысл» в инновационных ситуациях (Абакумова, Кагермазова, 2008; Асмолов, Шехтер, Черноризов, 2017; Кривошеева, 2020). Среди совокупности субъективных детерминант конструктивной социализации студента рангом приоритетных наделяются: мотивация достижения и дичностного роста, выраженность стремления утвердить свою субъектность в пространстве референтных отношений, сформированность многофункциональной компетентности, способность к многовекторной интерпретации и рефлексии опыта.

Современные социально-экономические преобразования российского общества, прогрессивные динамические трансформации в раздичных сферах общественной жизни выдвигают новые форматы развития дичности будущего специалиста. В современной психологи подчеркивают идея значимости разработки проблемы повышения адаптивного потенциала субъекта в период освоения взрослой жизни со всеми ее реалиями и рисками (Никоненко, 2018). Так как именно на этом этапе развития происходит дичностное самоопределение и вырабатывается модель активности в пространстве личного, социального и профессионального бытия, уникальность этого периода заключается в возможности активно апробировать на практике ценностно-смысловые ориентиры, жизнестойкость и свои возможности в приближении образа достижений.

В качестве субъективных предикторов успешности профессионального самоопределения студентов в условиях неопределенности и новых форматов профессионадьного обучения выступают ряд факторов: представление о себе как действующем субъекте, релевантное стремлению к успеху содержание мотивации, целеустремленность, независимость, креативность, готовность экспериментировать и проявдять надситуативную активность, дичностная устойчивость, эмоциональная стабильность, психологическая конструктивность (Головина, 2018; Тихонова, 2018).

С психологической стороны успех рассматривается как особая форма самореализации субъекта, продуцирующая ощущение психологического благополучия, самоуважение и доверие к самоэффективности, подтвержденной оценками референтных других (Джига, 2020; Непогодина, Ярушева, 2020).

Аичностный смысл достижения высоких результатов в контексте современных социальных трендов связан с повышением самооценки и усилением позитивного отношения к себе, уверенностью в возможности продуктивности в будущем. Здесь проявдяется объективная и субъективная значимость успеха 
студента в разных сферах. Субъективно значимый успех становится мощным мотиватором дальнейшего продвижения субъекта как в аутопсихологическом плане, так и в реальной деятельности.

Потребность в постоянном саморазвитии, самоинициация освоения новых векторов активности как показывают исследования психологов, связано с принятием успеха как значимой личностной ценности, представлением о престижности достижений и позитивных трансформаций, идентификацией с группой людей, способных эффективно решать проблемы (Соколович, 2020; Saseendran, Salman, 2019).

Выделяются основные векторы взаимосвязи «адаптивность - успешность»: повышение ресурсных возможностей дичности; приобретение конструктивного опыта; стабилизация установки на проявление компетентности и адекватной запросу ситуации активности; акцент на роли адаптации в осознании детерминации успеха. В работах психодогов доказано, вместе с тем, значение связи успешности дичности и надситуативной активности, аутопсиходогической компетентности, соразмерности конструктивности и риска в реализуемой дичностью активности, способностью к автономии и стремлением к трансформациям.

Как показывают исследования психологов, переживание успеха сопровождается позитивными эмоциями, способствуя усилению мотивации и ассимиляции опыта реальных достижений желаемого, утверждению позитивного самоотношения, формированию представления о себе как перспективной дичности. В достижении высокого уровня адаптивности студентов большую роль играет субъектная позиция, интегрированность субъективного контроля, ориентация на временную перспективу (Головина, 2018; Панкратова, 2018).

Повторяющийся опыт переживания ситуации успеха в раздичных сферах формируют субъективную базу для реализации пролонгированного успешного поведения в условиях современных рисков. В исследованиях психологов в качестве значимых детерминирующих успех разного типа факторов выделяются дичностные смыслы, характер смысложизненных ориентаций, адекватный выбор жизненной стратегии, четкость жизненных планов.

В современной психологии в совокупности основных детерминирующих факторов повышения адаптивности развивающейся дичности сегодня особо выделяют такие как: стимулирующая среда; влияние референтных взрослых, задающих тон; пространство для апробации социальной компетентности; способность к рефлексии опыта; просоциально ориентированная референтная группа; самоуважение, стремление к личностному росту; выраженность социогенных потребностей; активность. Сегодня психологи акцентируют внимание на стремлении молодых людей быть успешными в разных сферах жизни как современном тренде на фоне раздичных дефицитов компетентности (Звездина, 2015; Kayasheva, Khanova, 2019). 
В психодогических исследованиях показана взаимосвязь подноты и адекватности представлений студентов и успешной адаптации в инновационном пространстве современного профессионального образования. В частности, содержание представлений об условиях и возможности достижения успеха в учебно-профессиональной деятельности во многом зависит продуктивность предпринимаемых усилий и оптимальность привлекаемых ресурсов.

Переживание успешности сопряжено, как правило, с позитивным эмоциональным сопровождением действий человека и с радостью по поводу того, что достижение намеченного делает его значимой, востребованной, привлекательной дичностью, желаемой, одобряемой в современной социокультурной среде. Стремление к успеху, с точки зрения психологов, является одна из фундаментальных потребностей субъекта, удовлетворение которой является, по существу, доказательством самоэффективности и повышает статус психологического благополучия. В современной социальной ситуации развития студентов присутствуют социокультурные и образовательные риски: противоречие декларируемых возможностей и надежности их обеспечения; быстрая смена ориентиров и трендов; существенное изменение форматов обучения; приоритет дистанционных форм взаимодействия; повышенная стрессогенность среды; энтропийность условий реализации деятельности. При этом успешность является сегодня одной из ведущих в системе иерархизированных жизненных ценностей студентов. Это актуализирует проблему изучения алгоритмов и психологических механизмов усиления адаптационных механизмов развивающегося субъекта (Назаров, 2020).

В современных психологических исследованиях, показано, что существует обоюдная взаимосвязь между мотивацией достижения успеха, активностью, продуктивностью личности, уровнем адаптивности и успешности, выражающаяся в том, что более адаптированная дичность будущих специалистов явдяется результатом его продуктивной социализации на более ранних этапах развития и необходимым условием конкурентоспособности в будущем (Понкпатова, 2018; Соколова, 2020). В качестве критериев высокой адаптивности в психологии выделяется ряд позиций: наличие четких представлений о стандартах поведения и возможностях настоящей ситуации; толерантность к стрессу; эффективность усилий, результативность деятельности, оптимальность использования индивидуальных ресурсов; готовность к развитию в новых условиях среды; устойчивость дичности. Предметное изучение содержания представлений студентов о сущности связи «адаптивность - успешность» способствует созданию адекватных программ по усилению конструктивного развития личности студентов.

Отмечается надичие двусторонней взаимосвязи адаптивность-успешность, которая выражается в том, что адаптация становится базой для достижения дичностью успеха, достижение которого, в свою очередь, повышает возможность адаптации к постоянно меняющимся условиям. 
Следует отметить, что как высокий уровень адаптации, так и успешность личности взаимосвязаны определенным образом ее стремлением к саморазвитию и позитивным трансформациям, адекватным вызовам современности (Shcherbakova, 2019). Способность дичности использовать свои психологические ресурсы напрямую связана с достижением субъективно значимой цели, реализацией желаемой модели будущего.

Обратная связь рассматривается как механизм коррекции активности за счет анализа оценок окружающими как результатов, так и способов деятельности, понимания ожиданий, требований, предъявляемых к личности социумом.

Яркой психологической особенностью студенчества явдяется высокая мобильность и восприимчивость к новым тенденциям, инновациям и трендам: социокультурным и образовательным, готовность отходить от стереотипов и искать новые способы достижения успеха.

\section{Методы}

В исследовании исподьзовались следующие методы: анкета «Детерминанты успеха и способы его достижения» (Т. Н. Щербакова, О. Киреев), тест-опросник «Потребность в достижении» (Ю. М. Орлов, В. И. Шуркин, А. П. Орлова); методика «Социально-психологическая адаптация» (Р. Даймонд, К. Роджерс). В исследовании приняли участие студенты психологи, обучающиеся в ДГТУ.

\section{Резудьтаты исследования}

Анализ полученных результатов показывает, что в представлениях $45 \%$ респондентов критерием высокого уровня адаптации дичности является успех, достижение цели. Достаточно большое количество студентов- 38 \% связывают успех с персонализацией как в реальном взаимодействии, так и в сети Интернет, с признанием в референтной группе. Представления студентов о связи адаптивности и успешности достаточно фрагментарны, в них чаще всего указывается на значимость желания человека повышать адаптивные способности для получения успеха $-49 \%$.

В плане рефлексии условий высокой адаптивности личности $34 \%$ студентов подчеркивают значение индивидуадьных ресурсов и опыта их успешного использования в раздичных ситуациях. Достаточно бодьшое кодичество студентов 37 \% считают, что адаптивность и успешность связаны неоднозначно, очевидно это следствие ограниченного понимания адаптации как приспособления.

В результате исследования выраженности потребности достижений было выявлено, что высокая степень данной потребности характерна для 56 \% респондентов, средний уровень демонстрируют 32 \% и 12 \% показывают недостаточную выраженность этого стремления.

Вместе с тем, совсем незначительная часть респондентов связывает достижение 
успеха с оптимизмом, способностью непрерывно учиться в раздичных ситуациях, компетентностью в общении. Отмечается также вдияние устойчивости личностной и эмоциональной в достижении успеха и адаптации в условиях неопределенности. По мнению респондентов-студентов важно так же научиться анализировать и «психологически примерять» опыт других в достижении успеха для построения эффективной траектории продвижения. В качестве критериев адаптивности и успешности личности респонденты называют объективные достижения, психологическое удовлетворение от своих способностей решать проблемы, чувство гордости за объективные результаты деятельности, рост желания развиваться, достижение признания, освоение новых социальнопсихологических ролей.

Студенты выделяют ряд субъективных факторов, обеспечивающих высокую адаптивность и успешность:

- выраженную мотивацию достижения результатов и желаемых образов будущего;

- способность к самосовершенствованию качеств, способствующих успеху;

- гибкость и, одновременно, жизнестойкость;

- заинтересованность в расширении своего вдияния и возможностей в будущем.

В результате исследования были выявлены психологические барьеры адаптации в условиях современных рисков: неадекватная оценка своих ресурсов и ограничений, дефициты конструктивной «обучающей» обратной связи, недостаточное понимание специфики современной ситуации, затруднения рефлексии и прогностики.

\section{Обсуждение резудьтатов}

Высокий уровень развития потребности в достижениях пробуждает инициативность, активность и целеустремленность, стремление учесть и правильно оценить возможности ситуации, способность отстаивать свои интересы.

В оценке адаптации студентов можно выдедить тенденцию к нормативной адаптивности и стремление «психологически соответствовать» новым контекстам реализации учебно-профессиональной деятельности.

Таким образом, можно говорить о надичии связи степени адаптивности и успешности личности студентов. Социокультурные и образовательные риски современной социальной ситуации развития студентов продуцируют особые требования к адаптивности дичности и мотивации достижения успеха. Содержание, полнота, структурированность и четкость представлений студентов во многом определяет продуктивность адаптивной активности и вероятность повышения успешности. Понимание специфики проявлений неопределенности в современной ситуации профессионадизации человека способствует 
формированию устойчивости личности к энтропии. Общая тенденция оценки адаптивности студентов в ситуации неопределенности связана с тремя параметрами: продуктивность, жизнестойкость, конструктивность.

\section{Закдючение}

Анализ полученных результатов позволяет говорить о целесообразности разработки программ психологического обеспечения конструктивной адаптации студентов в условиях современных рисков как фактора повышения их успешности. Содержание такой программы должно интегрировать усиление мотивации роста, развитие компетентности, совершенствование рефлексивных и прогностических способностей.

\section{Авторы заявияют об отсутствии конфдикта интересов.}

\section{Дитература}

Абакумова И. В., Кагермазова И. Ц. Смысловые коммуникации в учебном процессе: теория и технологии направленной трансляции смыслов в обучении: Монография. М.: Нальчик: Изд-во М. и В. Котляровых, 2008. 325 с.

Асмолов, А. Г., Шехтер Е. Д., Черноризов А. М. Преадаптация к неопределенности как стратегия навигации развивающихся систем: маршруты эводюции // Вопросы психологии. 2017. № 4. С. 3-27.

Головина С. Г. Отношение к успеху и мотивация успешности студенческой молодежи // Тенденции развития науки и образования. 2018. № 43-3. С. 69-72.

Джига Н. А. Взаимосвязь самоотношения студентов с мотивацией достижения успеха // Вестник Барановичского государственного университета. 2020. № 8. C. 78-83.

Звездина Г. П. Инициация исследовательской активности студентов посредством участия в НИР // Субъект профессиональной деятельности: стратегии развития и риски: материалы Международной научно-практической конференции. Ростов-на-Дону: ДГТУ, 2015. С. 54-58.

Кривошеева А. С. Взаимосвязь прокрастинации и мотивации достижения успеха у студентов университета // Научно-практические исследования. 2020. № 10-2 (33). С. 14-18.

Назаров С. М. Психологические барьеры на пути к достижению успеха в профессиональной деятельности // Современные исследования проблем управления кадровыми ресурсами: материалы V Международной научно-практической конференции. Серпухов: ООО «Эдельвейс», 2020. С. 50-55.

Непогодина А. В., Ярушева С. А. Уровень самооценки как фактор успеха профессиональной деятельности // Управление, экономика и общество - 2020: проблемы и пути развития: материалы Международной научно-практической 
конференции: сборник статей. Челябинск: Издательство Челябинского Государственного университета, 2020. С. 118-120.

Никоненко Н. В. Взаимосвязь эго-состояния дичности и мотивации успеха // Мир педагогики и психологии. 2018. № 1(18). С. 107-112.

Панкратова И. А. Особенности взаимосвязи представлений об успехе и мотивации успешной деятельности у студентов // Известия Южного федерального университета. Педагогические науки. 2018. № 7. С. 105-110.

Соколович Е. А. Мотивация достижения успеха и мотивация избегания неудач у индивидов с разными уровнями и видами перфекционизма в период ранней взрослости // Право. Экономика. Психология. 2020. № 3 (19). С. 105-109.

Тихонова Н. Е. Факторы жизненного успеха и социального статуса в сознании россиян // Вестник Института социологии. 2018. Т. 9. № 4 (27). С. 11-43.

Kayasheva O. I., Khanova Z. G. The role of psychology students' reflexivity in securing professional success // EurAsian Journal of BioSciences. 2019. Vol. 13. Issue 2. P. 2051-2056.

Saseendran H., Salman S. Influence of Entrepreneurship Psychology on Small Business Creation and Organisational Success // Small Enterprises Development, Management \& Extension Journal. 2019. Vol. 46. Issue 3. P. 205-216. DOI: $\underline{10.1177 / 0970846419871112}$

Shcherbakova T., Misirov D., Akobyan M., Zhitnaya I. Psychological aspects of security culture development for modern students // International Scientific Conference: "Achievements and Perspectives of Philosophical Studies" (APPSCONF-2019), SHS Web Conf. Vol. 72, 2019. 03010. DOI: 10.1051/shsconf/20197203010

\section{References}

Abakumova, I. V., \& Kagermazova, L. Ts. (2008). Semantic communications in the educational process: theory and technologies of directed translation of meanings in teaching: Monograph. Moscow; Nalchik: Publishing house of M. and V. Kotlyarov. (in Russ.).

Asmolov, A. G., Shekhter, E. D., \& Chernorizov, A. M. (2017). Preadaptation to uncertainty as a strategy for navigation of developing systems: routes of evolution. Questions of Psychology, 4, 3-27. (in Russ.).

Golovina, S. G. (2018). Attitude to success and motivation of success of student youth. Trends in the Development of Science and Education, 43-3, 69-72. (in Russ.).

Jiga, N. D. (2020). The relationship of students' self-attitude with the motivation to achieve success. Vestnik of the Baranovichi State University, 8, 78-83. (in Russ.).

Kayasheva, O. I., \& Khanova, Z. G. (2019). The role of psychology students' reflexivity in securing professional success. EurAsian Journal of BioSciences, 13(2), 2051-2056.

Krivosheeva, A. S. (2020). The relationship between procrastination and motivation for achieving success among university students. Scientific and Practical Research, 10-2(33), 14-18. (in Russ.). 
Nazarov, S. M. (2020). Psychological barriers on the way to achieving success in professional activity. In: Modern studies of problems of human resources management. Proceedings of the V International Scientific and practical conference (pp. 50-55). Serpukhov: OOO «Edel'veys». (in Russ.).

Nepogodina, A. V., \& Yarusheva, S. A. (2020). The level of self-assessment as a factor of success of professional activity. In: Management, economy and society-2020: problems and ways of development. Proceedings of the International Scientific and Practical conference: collection of articles (pp. 118-120). Chelyabinsk: Chelyabinsk State University Publishing House. (in Russ.).

Nikonenko, N. V. (2018). The relationship between the ego-state of the individual and the motivation for success. The World of Pedagogy and Psychology, 1 (18), 107112. (in Russ.).

Pankratova, I. A. (2018). Features of interrelation of ideas about success and motivation of successful activity among students. Izvestiya Yuzhnogo Federalnogo Universiteta. Pedagogical Sciences, 7, 105-110. (in Russ.).

Saseendran, H., \& Salman, S. (2019). Influence of Entrepreneurship Psychology on Small Business Creation and Organisational Success. Small Enterprises Development, Management \& Extension Journal, 46(3), 205-216. DOI: 10.1177/0970846419871112

Shcherbakova T., Misirov D., Akobyan M., \& Zhitnaya I. (2019). Psychological aspects of security culture development for modern students. In: International Scientific Conference: "Achievements and Perspectives of Philosophical Studies" (APPSCONF-2019). SHS Web Conf., 72, 03010. DOI: 10.1051/shsconf/20197203010

Sokolovich, E. A. (2020). Motivation to achieve success and motivation to avoid failure in individuals with different levels and types of perfectionism in the period of early adulthood. Right. Economy. Psychology, 3(19), 105-109. (in Russ.).

Tikhonova, N. E. (2018). Factors of Life success and social status in the minds of Russians. Vestnik of the Institute of Sociology, 9(4(27)), 11-43. (in Russ.).

Zvezdina, G. P. (2015). Initiation of research activity of students through participation in research. In: Subject of professional activity: development strategies and risks. Proceedings of the International Scientific and Practical Conference (pp. 54-58). Rostov-on-Don: DSTU. (in Russ.). 